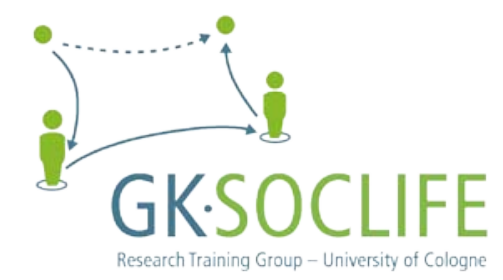

GK SOCLIFE

WORKING PAPERS SERIES

16

Octomber 2012

The fixed effect as an alternative to multilevel

analysis for cross-national analyses

\title{
Katja Möhring
}

SOCLIFE University of Cologne 


\title{
The fixed effects approach as an alternative to multilevel analysis for cross-national analyses
}

\author{
Katja Möring
}

\begin{abstract}
Multilevel models that combine individual and contextual factors are increasingly popular in comparative social science research; however, their application in country-comparative studies is often associated with several problems. First of all, most data-sets utilized for multilevel modeling include only a small number $(\mathrm{N}<30)$ of macro-level units, and therefore, the estimated models have a small number of degrees of freedom on the country level. If models are correctly specified paying regard to the small, level-2 $\mathrm{N}$, only a few macro-level indicators can be controlled for. Furthermore, the introduction of random slopes and cross-level interaction effects is then hardly possible. Consequently, (1) these models are likely to suffer from omitted variable bias regarding the country-level estimators, and (2) the advantages of multilevel modeling cannot be fully exploited.

The fixed effects approach is a valuable alternative to the application of conventional multilevel methods in country-comparative analyses. This method is also applicable with a small number of countries and avoids the country-level omitted variable bias through controlling for country-level heterogeneity. Following common practice in panel regression analyses, the moderator effect of macro-level characteristics can be estimated also in fixed effects models by means of cross-level interaction effects. Despite the advantages of the fixed effects approach, it is rarely used for the analysis of cross-national data.

In this paper, I compare the fixed effects approach with conventional multilevel regression models and give practical examples using data of the International Social Survey Programme (ISSP) from 2006. As it turns out, the results of both approaches regarding the effect of cross-level interactions are similar. Thus, fixed effects models can be used either as an alternative to multilevel regression models or to assess the robustness of multilevel results.
\end{abstract}




\section{Introduction*}

Multilevel models (also known as random effects models or mixed models) ${ }^{1}$, which combine individual and context indicators, are increasingly popular in comparative social science research $^{2}$; however, their application in this field is often problematic. In sociological and social policy analyses, multilevel models are frequently used to analyze individuals nested in countries. The application of multilevel models for this kind of research is confronted with several problems due to some characteristics of international survey data-sets which are used for these analyses: First, the country selection is usually not based on a random sample. Second, these data-sets often include around 25 countries or less (see Table 1). Consequently, multilevel models on the basis of international surveys have a low number of degrees of freedom on the country level. Therefore, many advantages of multilevel models, such as the introduction of random slopes and cross-level interaction effects, cannot be applied for statistical reasons. If models are correctly specified, paying regard to the small country-level $\mathrm{N}$, only a low number of macro-level indicators can be controlled for. As a consequence, the country-level estimators of these models are likely to suffer from omitted variable bias.

In this paper, I present the fixed effects approach ${ }^{3}$ as an alternative to the application of multilevel methods for country comparisons. Fixed effects models are also applicable to small samples and avoid the country-level omitted variable bias. Here, macro-level characteristics cannot be directly included, but their moderator effect can be estimated by means of crosslevel interaction effects. This procedure stems from panel regression models, but is rarely used to analyze country-comparative multilevel data.

The paper proceeds as follows: First, I summarize the problems of the application of conventional multilevel regression for country comparisons and describe the alternative of fixed effects regression models and their advantages. Next, I outline the application of fixed effects models for country-comparative analyses. This is followed by a practical research example using data of the International Social Survey Programme (ISSP) of 2006. Here, I demonstrate the application of the fixed effects approach and compare it with the results of

\footnotetext{
* I thank Alexander W. Schmidt, Olli Kangas, and Marco Giesselmann for helpful comments. All remaining errors are mine.

${ }^{1}$ Following common practice, I here use the term multilevel (regression) models for the currently most commonly applied multilevel technique in comparative analysis, the so-called random effects or mixed models.

2 A keyword search for "multilevel” in the archive of the European Sociological Review gives 122 results for the period 2008-2012 and only 35 results for the period 2003-2007.

${ }^{3}$ The terms "fixed effects" and "country fixed effects" are used synonymously in this text, as it only refers to data with individuals nested in countries.
} 
conventional multilevel models. Finally, I conclude and give recommendations for the application of the fixed effects approach.

\section{Problems of the application of multilevel models for country comparisons}

Social sciences are interested in explaining social phenomena. Often, these phenomena are dependent on the characteristics of a person as well as of the country where the person lives. For example, attitudes towards governmental redistribution may depend upon individual factors, such as educational background (Arrow A in Figure 1), as well as upon economic and political factors, such as income inequality and/or the level of social assistance benefits of a country (Arrow B in Figure 1). Therefore, in many cases the explanation of social phenomena involves multilevel hypotheses (Hox 2010: 4).

Figure 1: Multilevel explanatory scheme

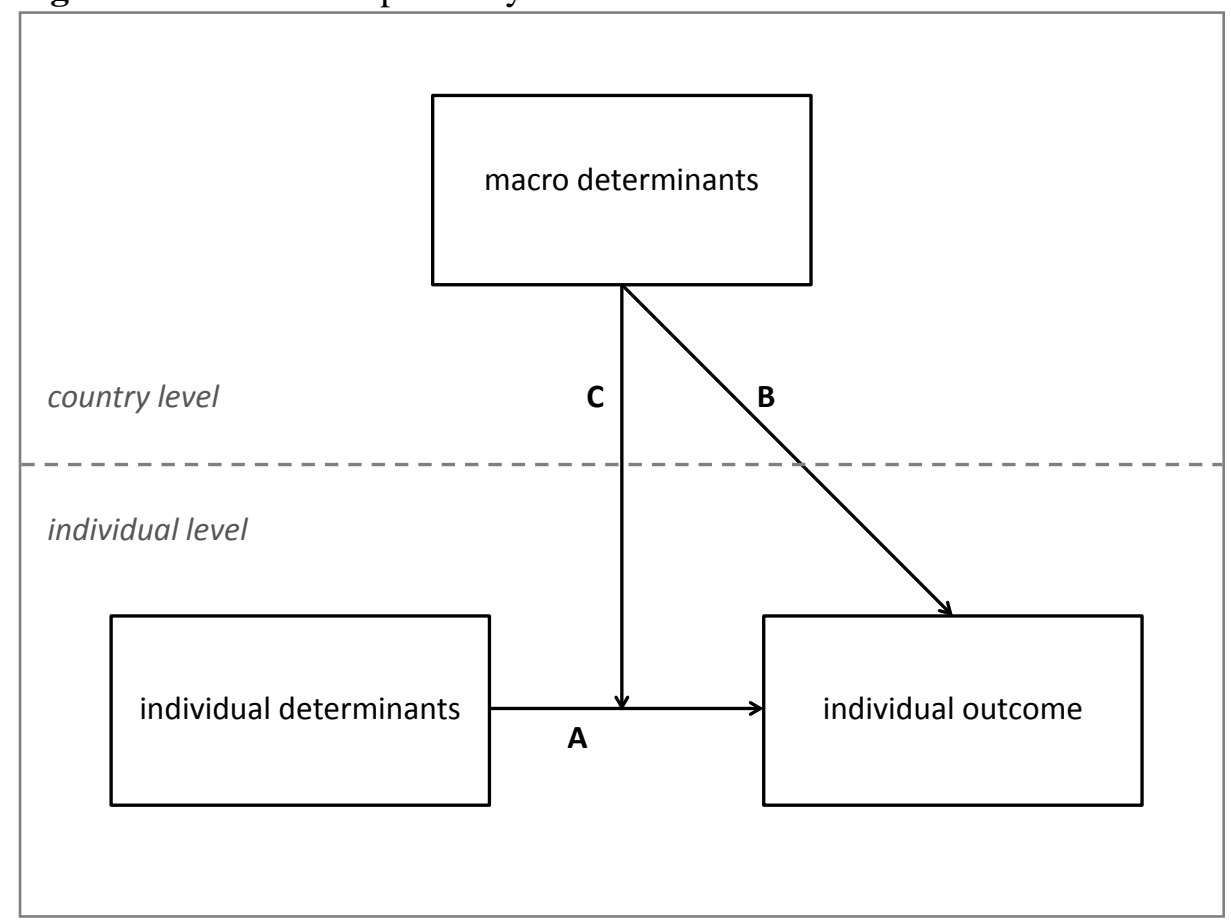

Source: Author

A straightforward strategy to analyze these kinds of research questions and hypotheses is the application of multilevel regression techniques. Multilevel models are specifically suitable for research questions that address (a) the effect of macro-level factors on an individual-level outcome in a nested structure (Arrow B in Figure 1), and (b) the interaction effect of individual and macro-level factors, which represents the moderator effect of a country indicator (Arrow C in Figure 1).

Because of the existence of more and more easily accessible international survey datasets as well as the development of computer technology and the availability of a range of 
specific analysis programs (HLM, MLwiN, Mplus), multilevel regression techniques have been applied increasingly in recent years. It is commonly accepted that a hierarchical datastructure makes the application of multilevel modeling inevitable. For example, according to Hox (2010: 1), multilevel models are necessary to account for the hierarchical structure and successive sampling of the data with individuals nested in national units. The underlying research question in multilevel analyses is which factors explain the variation between countries, with respect to a specific individual-level outcome. Multilevel modeling allows the disentangling of the variance to the individual and the country level and the investigation of whether country differences exist with respect to the level (intercept) and/or the strength and direction (slope) of an effect.

Multilevel modelling originated from educational research. Here, typically pupils nested in classes (and eventually those nested in schools as third level) are analysed. Two main differences exist between these educational data-sets and the international surveys typically used for multilevel analyses in social sciences:

\section{No random sample at the upper level}

In most international surveys, which include individuals in several countries, the selection of countries is not a random, but a convenient sample of those countries where researchers are willing and have the financial means to participate in the study.

\section{Small $\mathbf{N}$ at the upper level}

Commonly used international survey data-sets include between 11 and 31 countries, and only one available survey contains more than 50 countries (see Table 1). Consequently, the estimated models rely on few national units and have a low number of degrees of freedom on the country level.

Because of these limitations of the available data-sets, multilevel modeling in social sciences faces several problems. In the following, I will expand on three of these. First, influential cases on the country level can have a strong effect. Van der Meer et al. (2010) showed that the country-level slope estimators are likely to be unreliable due to influential cases for small sample sizes. The authors demonstrated that the main conclusion on a slope estimate drawn from a study of 53 countries by Ruiter and De Graaf (2006) relied entirely on three countries in the sample with outlier values for the main macro-level explanatory factor. As most international survey data-sets have much smaller country-level sample sizes, the problem of influential outliers is even more serious. On the basis of a simulation analysis, Maas and Hox (2005) concluded that only samples with more than 50 macro units produce 
unbiased multilevel estimators. Following this recommendation, multilevel analysis is virtually not applicable for country-comparative research.

Table 1: Number of countries included in international survey data-sets (exemplary)

\begin{tabular}{|l|l|}
\hline International survey data-set & Number of countries \\
\hline CNEF project (Cross-National Equivalent File) & $\begin{array}{l}7 \text { (harmonized national panel data- } \\
\text { sets) }\end{array}$ \\
\hline ESS (European Social Survey) & $\begin{array}{l}\text { up to 27 countries, depending on } \\
\text { wave }\end{array}$ \\
\hline Eurobarometer & $\begin{array}{l}13 \text { to } 47 \text { countries, depending on } \\
\text { wave }\end{array}$ \\
\hline EVS (European Values Survey) & $\begin{array}{l}\text { up to 27 countries, depending on } \\
\text { wave }\end{array}$ \\
\hline $\begin{array}{l}\text { EU-SILC (European Union Statistics on Income and Living } \\
\text { Conditions) }\end{array}$ & 6 to 12 countries, depending on wave \\
\hline ISJP (International Social Justice Project) & 26 (2006 wave) \\
\hline ISSP (International Social Survey Programme) & $\begin{array}{l}11 \text { to 14 countries, depending on } \\
\text { wave }\end{array}$ \\
\hline $\begin{array}{l}\text { SHARE (Survey of Health, Ageing and Retirement in } \\
\text { Europe) }\end{array}$ & $\begin{array}{l}\text { up to 53 countries, depending on } \\
\text { wave }\end{array}$ \\
\hline WVS (World Values Survey) & \multicolumn{2}{|l}{} \\
\hline
\end{tabular}

Second, the low number of macro-level units substantially limits the possibilities to exploit the full potentials of multilevel modeling. In multilevel models, the estimation not only of macro-level predictors, but also of the random components and the random slopes, relies on the degrees of freedom of the country level. Consequently, a multilevel analysis with a low number of macro-level units faces the same limitations as a small survey of, for example, 20 respondents: The possible number of country-level predictors in the model is rather low. Furthermore, the possibilities to test random slope estimators and to include cross-level interaction effects are rather limited as the number of parameters in the models increases quickly (see Table 2).

Table 2: Number of parameters in a multilevel model with $p$ explanatory variables at the individual level and $q$ explanatory variables at the country level

\begin{tabular}{|ll|}
\hline Parameters & Number \\
Intercept & $\mathrm{I}$ \\
Lowest-level error variance & 1 \\
Fixed slopes for the lowest-Ievel predictors & $\mathrm{P}$ \\
Highest-Ievel error variance & $\mathrm{I}$ \\
Highest-Ievel error variances for these slopes & $\mathrm{P}$ \\
Highest-Ievel covariances of the intercept with all slopes & $\mathrm{P}$ \\
Highest-level covariances between all slopes & $\mathrm{p}(\mathrm{p}-1) / 2$ \\
Fixed slopes for the highest-Ievel predictors & $\mathrm{q}$ \\
Fixed slopes for cross-level interactions & $\mathrm{pxq}$ \\
\hline
\end{tabular}

Source: Hox (2010), 55. 
Third, omitted variable bias regarding the country-level estimators is likely to occur in multilevel models because of a small country-level sample size. The basic assumption of multilevel (random effects) models is that the country-level error term is uncorrelated with all other variables in the model and the individual-level error term (Hox 2010: 13). If not all relevant variables are controlled for, the country-level estimators are likely to be faulty due to omitted variable bias (Allison 2009). As described, because of the small number of upperlevel units, only few variables on the country level can be included. Therefore, it is virtually impossible to control for all relevant variables on the country level, and the existence of omitted variable bias is very likely ${ }^{4}$. As a consequence, researchers may find seemingly significant country-level effects that, in fact, are triggered by (an) unobserved factor(s) (Snijders 2005) $)^{5}$. One prevalent solution for this problem is to 'test' stepwise the macro indicators in separate models before estimating the final model with the most significant macro indicators. Considering the problem described above, this procedure also involves the risk of biased (but maybe significant) estimators (Schmidt 2012).

To sum up, if multilevel models are correctly specified, paying regard to the small, country-level N, then only a few macro-level indicators can be controlled for. Furthermore, the introduction of random slopes and cross-level interaction effects is then hardly possible. Consequently, (1) these models are likely to suffer from omitted variable bias, and (2) the advantages of multilevel modeling cannot be fully exploited.

Despite these problems, multilevel techniques are influentially used in countrycomparative research also for data-sets with a very small country-level N. Mostly, the researchers employ the strategies of either including only one or a few macro indicators in the analysis or testing successively different macro-level variables (see Engelhardt 2012; Pichler and Wallace 2009; Semyonov et al. 2006). The application of multilevel methods with a sample of less than 15 countries certainly is most problematic. However, for other research questions, too, multilevel methods are utilized, although their application is unnecessary or even inappropriate. For example, researchers may be interested only in the effect of individual-level factors and want to test whether these effects are universally present regardless of the national context (see Goerres 2007; Oskarrson 2010; Besley 2006). The same applies to studies where the authors are not interested in the direct effect of macro

\footnotetext{
${ }^{4}$ Also on the micro level, omitted variable bias may occur due to unobserved individual factors. However, due to the higher numbers of observation on this level, it is possible to include more variables to avoid this problem. By means of longitudinal/panel data with repeated measures the problem of individual-level omitted variable bias can be tackled.

${ }^{5}$ This problem is even intensified by the fact that the common data-sets for comparative studies in social sciences mostly include highly connected (Western) developed countries, and thus, country characteristics are likely to be dependent on each other.
} 
variables, but rather in their moderator effect, i.e., in the cross-level interaction effect (see Koster and Bruggeman 2008). In both cases, the application of multilevel regression techniques is inappropriate, because it is only controlled for those country-level characteristics that are actually included in the model. Regression models that generally control the country-level heterogeneity would be preferable to analyze these research questions.

The fixed effects approach is an alternative to the application of conventional multilevel methods in country-comparative analyses regarding the problems of omitted variable bias on the country level and the limitation of adding random slopes and cross-level interaction effects. This method is also applicable with small country samples and avoids the country-level omitted variable bias through controlling for country-level heterogeneity by means of dummy variables (Allison 2009: 14). Despite the advantages of the fixed effects approach, it is rarely used for the analysis of cross-national data. One reason for this is that on first impression, this approach seems to be entirely incapable of testing country-level effects. However, following common practice in panel regression analyses, the moderator effect of macro-level characteristics can be estimated also in fixed effects models by means of crosslevel interaction effects ${ }^{6}$.

The central conceptual difference between the multilevel and the fixed effects approaches is that the former intends to explain the country-level variation, whereas the latter controls for this variation. Consequently, fixed effects models are fruitful for analyses with a small number of countries to examine the effect of individual-level variables - for instance, to test whether an individual-level effect is universal- and of cross-level interactions controlling for other factors and 'random noise' related to the country level. In the following, I will outline the procedure of applying the fixed effects approach to country-comparative analyses.

\section{How to apply the fixed effects approach for multilevel analyses}

\section{Conventional multilevel regression models}

Standard ordinary least squares (OLS) regression models depend on the assumption of the independency of observations, which is violated in hierarchically nested data. If the dependency of observations within groups is not accounted for, the estimated standard errors are too small and falsely significant results may be the consequence (Hox 2010: 4). Therefore,

\footnotetext{
${ }^{6}$ With time series data, it is possible to estimate within-effects of macro variables (Schmidt 2012). However, here we focus on cross-sectional analysis.
} 
multilevel models are applied to account for the nested structure of the data - the fact that inhabitants of the same country are likely to be more similar than individuals from different countries. Accordingly, one part of the variation in multilevel analyses is related to the individual level and another part to the country level, because of the shared characteristics of respondents from one country. Therefore, in multilevel models the error term is split into the country-specific part $u_{j}$ and the part specific to each observation within these units $e_{i j}$. These error terms together form the random part of the model. To illustrate this point, we take a look at the simple (random intercept) multilevel model with $i=1, \ldots, n$ individuals, nested in $j=1, \ldots . N$ countries:

$$
y_{i j}=\underbrace{\gamma_{00}+\beta_{1} x_{1 i j}+\cdots+\beta_{k} x_{k i j}+\gamma_{1} z_{1 j}+\cdots+\gamma_{l} z_{l j}}_{\text {fixed part }}+\underbrace{u_{j}+e_{i j}}_{\text {random part }}
$$

with

$y_{i j}$ : Individual-level dependent variable of observation $i$ in country $j$

$\gamma_{00}$ : Intercept over all countries (the country specific intercept $\gamma_{0 j}$ equals $\gamma_{00}+$ $\left.u_{j}\right)$

$x_{k i j}$ : Independent individual-level variable number $k$ of observation $i$ in country $j$

$\beta_{k}$ : Coefficient of individual-level variable number $k$

$z_{l j}$ : Independent country-level variable number $l$ of country $j$

$\gamma_{l}$ : Coefficient of country-level variable number $l$

$u_{j}$ : Error term (residual variation) for each country $j$

$e_{i j}$ : Error term (residual variation) for observation $i$ within country $j$

The fixed part of a multilevel equation consists of the intercept $\gamma_{00}$ - the grant mean - and the vectors of all individual-level $x_{i j}$ and country-level dependent variables $z_{j}$ with the estimated coefficients $\beta$ and $\alpha$. The observation-specific error term $e_{i j}$ includes all the unobserved heterogeneity that is related to each single observation $i$ in county $j$, the so-called idiosyncratic error (Andreß et al. forthcoming). The country-specific error term $u_{j}$ captures the unobserved heterogeneity related to the macro unit, and the country-specific error term is treated as a set of normally distributed random variables. Consequently, multilevel (random effects) models rely on the rather demanding assumption that these random variables are independent of all other variables in the model (Allison 2009; Hox 2010: 13).

Coming back to the description of the multilevel approach: An advantage is the variance components, which allow an examination of the country-level variation $u_{j}$ more closely and to find factors which explain this variation. The random intercept model in E.1 is used to analyze the between-country variance, which stems from different levels of the outcome variable. Furthermore, country differences may also exist in the effect-direction 
and/or the effect-strength of a certain independent variable on the outcome variable. To examine this, we utilize random slope models, which contain variance components for certain individual-level variables. This point is illustrated in equation E.2, where the interaction effect $u_{1 j} x_{1 i j}$ represents the random slope of the individual-level variable $x_{1 i j}$.

$$
y_{i j}=\gamma_{00}+\gamma_{10} x_{1 i j}+\cdots+\beta_{k} x_{k i j}+\gamma_{01} z_{1 j}+\cdots+\gamma_{0 l} z_{l j}+u_{0 j}+u_{1 j} x_{1 i j}+e_{i j}
$$

Usually, multilevel techniques are applied in a stepwise procedure. Before, individual- and macro-level predictors are included, a so-called null-model, a regression without predictors, is estimated. The null-model is used to identify how much unexplained variation stems from the country level. Therefore, the intraclass correlation (ICC) is calculated, which gives information about the proportion of country-level variance of the total variance (Hox 2010: 15).

\section{Fixed effects regression models}

The main advantage of international surveys is that the data contains observations from several macro units. We can use this advantage to control for the variance related to the country level by means of country fixed effects. In this way, the fixed effects approach has one central advantage over conventional multilevel models. In the latter, the country-specific error term is assumed to be normally distributed and independent of the other variables in the model and the individual-level error term (Hox 2010: 13). In contrast, in fixed effects regression models the country-specific error term is treated as a set of fixed numbers, which are estimated in the model. Thus, it is irrelevant whether the error term is independent of the other variables in the model (Allison 2009: 21).

To illustrate this point, we take a look again at the general regression equation of multilevel models E.1 where both parts of the error term belong to the random part of the model. To transfer this multilevel into a fixed effects equation, we simply change the affiliation of the country-specific error term. As $u_{j}$ is now explicitly estimated in the model, it belongs to the fixed part of the equation:

$$
y_{i j}=\underbrace{\gamma_{0}+\beta_{1} x_{1 i j}+\cdots+\beta_{k} x_{k i j}+\boldsymbol{\alpha}_{\mathbf{1}} \boldsymbol{u}_{\boldsymbol{j} \mathbf{1}}+\cdots+\boldsymbol{\alpha}_{\boldsymbol{N - 1}} \boldsymbol{u}_{\boldsymbol{j} N-\mathbf{1}}}_{\text {fixed part }}+\underbrace{e_{i j}}_{\text {random part }}
$$

with

$\alpha_{1} u_{j 1}+\cdots+\alpha_{n-1} u_{j n-1}$ : fixed effects for the N-1 countries in the data-set.

In practice, this is simply done by including dummy variables for $\mathrm{N}-1$ countries in the model. The predictors of the country dummies in the fixed effects model are actually the estimators 
of the country-specific error term $u_{j}$ (Allison 2009: 16). As described so far, the fixed effects approach controls for country-level heterogeneity and allows concentrating on the effect of the individual-level predictors. However, the approach can also be used for further analyses of the country-level variance, as I will demonstrate in the following.

In multilevel analysis, we want to examine whether the strength and/or the direction of a certain individual-level effect differs among countries —as we did with the random slope model before. To do this in the fixed effects approach, we interact the fixed country-level error terms $u_{j N-1}$ with the individual-level variable of interest $x_{1 i j}$ :

$$
\begin{aligned}
& y_{i j}=\gamma_{00}+\beta_{1} x_{1 i j}+\cdots+\beta_{k} x_{k i j}+\boldsymbol{\delta}_{\mathbf{1}} \boldsymbol{x}_{\mathbf{1 i j}} \boldsymbol{u}_{\boldsymbol{j} \mathbf{1}}+\cdots+\boldsymbol{\delta}_{\boldsymbol{N - 1}} \boldsymbol{x}_{\mathbf{1 i j}} \boldsymbol{u}_{j N-\mathbf{1}}+\alpha_{1} u_{j 1}+\cdots+ \\
& \alpha_{N-1} u_{j N-1}+e_{i j}
\end{aligned}
$$

In practice, we add N-1 interaction effects to the fixed effects model. To test whether these interactions significantly improve the prediction, a comparison of the models described in E.3 and E. 4 by means of an F-Test ${ }^{7}$ is useful.

The next step in multilevel modeling is usually to include macro variables and crosslevel interaction effects to explain this country-level variation. However, the main drawback of fixed effects models is that country-level variables cannot be estimated. After the inclusion of N-1 country dummies, no degrees of freedom are left on the country level. In other words, the country dummies explain all variance at the country level, and there is no variance left to be explained by additional country-level variables (Allison 2009). To solve this problem, we follow a common practice from panel data analyses. Instead of modeling the direct effect of country factors, we include interaction effects of those factors with individual-level variables in the model. These interaction effects vary among as well as within countries, and thus, can be estimated together with the country dummies in the model. In conceptual terms, the crosslevel interaction effect represents the moderator effect of a macro variable (Arrow $\mathrm{C}$ in Figure 1). Thus, we are able to draw conclusions indirectly about the impact of country-level characteristics. Furthermore, for researchers who are mainly interested in a cross-level interaction effect, this procedure actually has an advantage over conventional multilevel modeling. Whereas in multilevel models we always have to be aware of whether we included all relevant factors on the macro level, this is not necessary in the fixed effects approach as here it is controlled for the country-level heterogeneity.

As explained above, the first step of a multilevel analysis is the calculation of the ICC of the null-model to examine what proportion of the variance stems from the country level. In

\footnotetext{
${ }^{7}$ Alternatively, a Likelihood ratio test for logistic regression.
} 
the fixed effects approach, this can be done with the estimation of a model that includes only the country dummies. The $\mathrm{R}^{2}$ value of this model, which provides information about the share of explained variance, is then equal to the ICC of the multilevel null-model.

\section{A research example}

\section{Data and variables}

For the estimations I use the data of the ISSP 2006 with 26 countries $^{8}$. To demonstrate the application of the fixed effects approach, I test a hypothesis of the relationship between support for governmental redistribution and income. The dependent variable is the support for governmental redistribution from the ISSP-question, "It should be the government's responsibility to reduce differences in incomes between rich and poor.” The answer categories are 4 "definitely should be”, 3 "probably should be”, 2 "probably should not be”, and 1 "definitely should not be". This scale is interpreted as continuous. As has been shown in previous research, people tend to refuse governmental redistribution the higher their income is (self-interest hypothesis; see Andreß and Heien, 2001; Blekesaune, 2007; Rehm, 2009). The strength of this individual-level relationship differs among countries because of their cultural and economic backgrounds. However, this contextual impact is heavily discussed in the literature (Dallinger 2010; Jæger 2006; Jæger 2009; Mau 2004). Thus, for the research example, we focus on a rather straightforward hypothesis and assume that a country's economic status intensifies the relationship of individual income and support for redistribution: The wealthier a country, the stronger is the negative association between individual income and support for redistribution.

As a main explanatory variable on the individual level, we include the respondent's income position measured in percentiles, which are estimated separately for each country (categories 1-10). To measure the wealth of the countries we use the gross domestic product per capita (GDP/C) in 1,000 dollars and purchasing power parity (PPP) adjusted. A crosslevel interaction effect of these two variables is included to operationalize the moderator effect of country wealth on individual income. Individual-level control variables are age and gender (male=1, female=0). Table A.1 in the appendix gives an overview of the included variables. In total, 24,973 observations are included in the models.

\footnotetext{
${ }^{8}$ Australia, Canada, Chile, Czech Republic, Denmark, Finland, France, Germany East, Germany West, Great Britain, Hungary, Ireland, Israel, Japan, Republic of Korea, Latvia, Netherlands, New Zealand, Norway, Poland, Portugal, Slovenia, Spain, Sweden, Switzerland, and USA.
} 


\section{Results and comparison}

To compare the results of the fixed effects and the multilevel approaches, several models are estimated (see Table 3 and Table 4). Models 1.1 and 2.1 are calculated to test how much variance stems from the upper level. For the multilevel approach, this is the so-called nullmodel without predictors (M 2.1). In case of the fixed effects approach, this is a model only with the 25 country dummies (M 1.1) ${ }^{9}$. Models 1.2 and 2.2 also include the micro-level variables age, gender, and income in percentiles. Models 1.3 and 2.3 are estimated to test whether individual income also has a 'slope effect': In the multilevel approach, a random slope is added (M 2.3); in the fixed effects approach, interaction terms of the income variable and the country dummies are included (M 1.3). Models 1.4 and 2.4 integrate the cross-level interaction effect. Whereas the multilevel model M 2.4 contains also the main effect of GDP/C, the fixed effects model M 1.4 includes only the cross-level interaction effect.

The share of variance from the country level is 9.5 percent, as indicated by the $\mathrm{R}^{2}$ of the fixed effects model M 1.1 and the ICC of the multilevel model M 2.1. The effects of the individual-level control variables age and gender are similar in the fixed effects and the multilevel models (see M 1.2 in Table 3 and M 2.2 in Table 4). With increasing age, respondents are more likely to support governmental redistribution. Men support redistribution significantly less than women. Also, the estimators of the main explanatory variable income are the same in both approaches and are in line with the self-interest hypothesis: The higher the individual income position of a respondent in a country is, the significantly lower is her/his support for governmental redistribution.

The multilevel random slope model M 2.3 shows a significant variance component of individual income, meaning that the slope of income on support varies among countries. This effect is confirmed in the fixed effects model 1.3, which contains interaction effects of the country dummies and the individual income. According to an F-test, model M 1.3 significantly improves the prediction compared to model M $1.2^{10}$. However, this relationship contributes only little to the explanation of differences in support for redistribution, as the low increase in the adjusted $\mathrm{R}^{2}$ value from 13.1 percent in model M 1.2 to 13.9 percent in model M 1.3 reveals.

\footnotetext{
${ }^{9}$ Australia has the largest sample size and is used as reference category in the fixed effects models.

${ }^{10} \mathrm{~F}(25,24919)=10.75 * * *$
} 
Table3: Fixed Effects models, dependent variable: Support for governmental redistribution

\begin{tabular}{|c|c|c|c|c|c|}
\hline & & M 1.1 & M 1.2 & M 1.3 & M 1.4 \\
\hline Gender: Male & & & $\begin{array}{c}-0.032^{* *} \\
(0.018)\end{array}$ & $\begin{array}{c}-0.034^{* *} \\
(0.019)\end{array}$ & $\begin{array}{l}-0.030^{*} \\
(0.019)\end{array}$ \\
\hline Age & & & $\begin{array}{c}0.003^{* * *} \\
(0.001)\end{array}$ & $\begin{array}{c}0.004^{* * *} \\
(0.001)\end{array}$ & $\begin{array}{c}0.003 * * * \\
(0.001)\end{array}$ \\
\hline Indiv. income & & & $\begin{array}{c}-0.060 * * * \\
(0.007)\end{array}$ & $\begin{array}{c}-0.076 * * * \\
(0.001)\end{array}$ & $\begin{array}{c}0.006 \\
(0.014)\end{array}$ \\
\hline $\begin{array}{l}\text { Cross-level } \\
\text { interaction }\end{array}$ & & & & & $-0.000 * * *$ \\
\hline $\begin{array}{l}\text { Indiv. Income } \\
\text { GDP/C }\end{array}$ & $*$ & & & & $(0.000)$ \\
\hline & & + Country-FEs & + Country-FEs & $\begin{array}{c}\text { + Country-FEs } \\
+ \text { IEs } \\
\text { Country*Income }\end{array}$ & + Country-FEs \\
\hline Constant & & $\begin{array}{c}2.778 * * * \\
(0.000)\end{array}$ & $\begin{array}{c}2.930 * * * \\
(0.038)\end{array}$ & $\begin{array}{c}2.993 * * * \\
(0.046)\end{array}$ & $\begin{array}{c}3.017 * * * \\
(0.043)\end{array}$ \\
\hline $\mathrm{N}$ & & 24973 & 24973 & 24973 & 24973 \\
\hline $\mathrm{R}^{2}$ & & 0.095 & 0.132 & 0.141 & 0.135 \\
\hline Adjusted $\mathrm{R}^{2}$ & & 0.094 & 0.131 & 0.139 & 0.134 \\
\hline
\end{tabular}

Table4: Multilevel models, dependent variable: Support for governmental redistribution

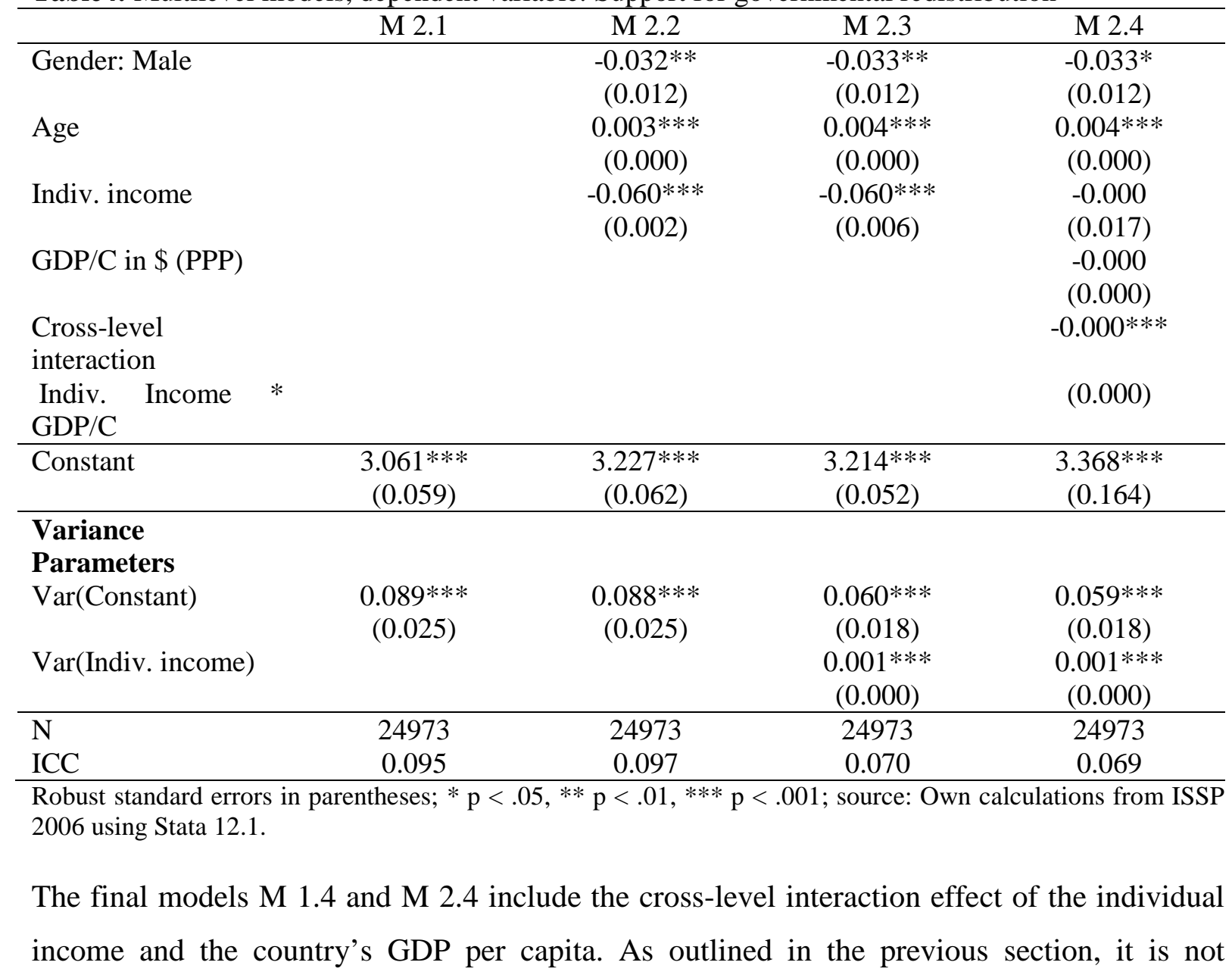


possible to include the main effect of GDP/C in the fixed effects model. However, the results of both models regarding the effect of the cross-level interaction are similar. In both cases, we find a very low negative $\approx\left(-0.000002^{* * *}\right)$ but a highly significant interaction effect. This means that the GPD/C slightly moderates the individual-level relation of income and support for governmental redistribution: The higher the GDP/C of a country, the more strongly richer people tend to refuse redistribution. Also, in both models the main effect of income is not significant anymore when the cross-level interaction with GDP/C is included.

To sum up, the fixed effects and the multilevel models produce similar results for this research example on the basis of 26 countries from the ISSP. The coefficients and significance levels of the individual-level variables, as well as of the cross-level interaction effect estimated with the fixed effects approach, are nearly identical to those of the conventional, multilevel models. Also the proportion of country-level variance, which is calculated by means of the null-model ICC, is reproduced in the fixed effects model.

\section{Conclusion}

As I demonstrated, the fixed effects approach is an alternative to the conventional multilevel models and can be utilized in similar way to investigate the direct and slope effects of individual-level variables, as well as the moderator effects of country-level variables. Therefore, this approach is useful in analyzing data from international surveys with a low number of country-level units, where conventional multilevel models can hardly be applied. Furthermore, fixed effects models are generally useful in assessing the robustness of multilevel results. In cases where researchers are mainly interested in individual-level or moderator effects, fixed effects models are an alternative to conventional, multilevel models. The fixed effects approach addresses the problem of macro confounders in multilevel regression. However, it does not tackle the general problem of international survey data that the cases on the upper level are simply limited and may include deviant cases. Therefore, the application of each analysis method generally calls for a thorough examination of the data before complex regression models are applied. As described before, the data of international surveys is typically sensitive to outliers on the country level. Measures such as the Cook’s D and such graphical examinations of the data as scatter or two-stage plots are useful for this ${ }^{11}$.

\footnotetext{
11 The Stata-programmes “multilevel tools" provide several solutions for outlier detection, etc. (Möhring/Schmidt 2012).
} 


\section{References}

Andreß, H.-J., Golsch, K., Schmidt, A. forthcoming. Applied Panel Data Analysis for Economic and Social Surveys, Berlin: Springer.

Andreß, H.-J. and Heien, T. 2001. Four worlds of welfare state attitudes? A comparison of Germany, Norway and the United states. European Sociological Review 17(4): 337-356.

Besley, J. C. 2006: The role of entertainment television and its interactions with individual values in explaining political participation. The Harvard International Journal of Press/Politics 11(2): 41-63.

Blekesaune, M. 2007. Economic conditions and public attitudes to welfare policies. European Sociological Review 23(3): 393-403.

Bryk, A.S. and Raudenbush, S.W. 1992. Hierarchical Linear Models in Social and Behavioral Research: Applications and Data Analysis Methods. Newbury Park, CA: Sage Publications.

Dallinger, U. 2010. Public support for redistribution: what explains cross-national differences? Journal of European Social Policy 20: 333-349.

Engelhardt, H. 2012. Late careers in Europe: Effects of individual and institutional factors. European Sociological Review 28(4): 550-563.

Goerres, A. 2007. Why are older people more likely to vote? The impact of ageing on electoral turnout in Europe. British Journal of Politics and International Relations 9(1): 90-121.

Hox, J. J. 2010. Multilevel Analysis. Techniques and Applications. 2. ed. New York, NY: Routledge (Quantitative methodology series).

Koster, F.; Bruggeman, J. 2008. The institutional embeddedness of social capital: A multilevel investigation across 24 European countries. Policy and Politics 36(3): 397-412.

Maas, C. J. M., Hox, Joop J. 2005. Sufficient sample sizes for multilevel modeling. Methodology 1(3): 86-92.

Möhring, K., Schmidt, A. W. 2012. Multilevel Tools - an ado-package for Stata, http://www.katjamoehring.de/?page_id=69 (last check: 01.08.2012).

Oskarrson, S. 2010. Generalized trust and political support: A cross-national investigation. Acta Politica 45(4): 423-443.

Pichler, F. and C. Wallace. 2009. What are the reasons for differences in job satisfaction across Europe individual, compositional, and institutional explanations. European Sociological Review 25: 535-549.

Pen World Table 7.0: Real GDP/C in international \$, PPP adjusted, G-K Method, http://pwt.econ.upenn.edu/php_site/pwt_index.php (last check: 01.08.2012).

Rehm, P. 2009: Risks and redistribution - an individual-level analysis. Comparative Political Studies 42(7): 855-881.

Ruiter, S. and De Graaf, N. D. 2006: National context, religiosity, and volunteering: Results from 53 countries. American Sociological Review 71: 191-210.

Schmidt, A. W. 2012. The Development of Public Demand for Redistribution. A PseudoPanel Model for Decomposing Within- and Between-Effects, WP 10-2012, GK SOCLIFE Working Paper Series.

Semyonov, M., Raijman, R., Gorodzeisky, A. 2006. The rise of anti-foreigner sentiment in European societies, 1988-2000. American Sociological Review 71: 426-449.

Snijders, T. A. B. and Bosker, R. J. 1994: Modeled variance in two-level models. Sociological Methods \& Research 22 (3): 342-363.

Snijders, T. A. B. and Bosker, R. J. 1999: Multilevel Analysis. An Introduction to Basic and Advanced Multilevel Modeling. London: Sage. 
Snijders T. A. B. 2005: Power and sample size in multilevel linear models. In: Everitt B S, Howell D C, (eds). Encyclopedia of Statistics in Behavioral Science. Vol. 3. Chicester: Wiley: 1570-1573.

Van der Meer, T., Te Grotenhuis, M., Pelzer, B. 2010. Influential Cases in Multilevel Modeling. American Sociological Review 75(1): 173-178. 


\section{Appendix}

Table A.1: Country means of included variables

\begin{tabular}{|l|r|r|r|r|}
\hline Country & \multicolumn{1}{l|}{$\begin{array}{l}\text { GDP/C in \$ } \\
\text { PPP }\end{array}$} & $\begin{array}{l}\text { Mean } \\
\text { indiv. } \\
\text { income }\end{array}$ & \multicolumn{1}{l|}{$\begin{array}{l}\text { Mean } \\
\text { share men }\end{array}$} & Mean age \\
\hline Australia & 41260.6 & 5.0 & 47.4 & 50.5 \\
\hline Canada & 38580.2 & 4.9 & 50.8 & 51.6 \\
\hline Chile & 13214.4 & 4.9 & 41.1 & 44.8 \\
\hline Czech Republic & 22651.9 & 5.1 & 42.3 & 49.4 \\
\hline Denmark & 37096.2 & 4.7 & 46.7 & 50.6 \\
\hline Finland & 33784.0 & 5.4 & 46.2 & 46.0 \\
\hline France & 32390.1 & 4.8 & 55.6 & 52.6 \\
\hline Germany East & 33632.3 & 4.9 & 47.8 & 49.6 \\
\hline Germany West & 33632.3 & 5.7 & 48.7 & 49.0 \\
\hline Great Britain & 36132.7 & 5.1 & 41.5 & 48.8 \\
\hline Hungary & 17684.2 & 5.4 & 44.8 & 48.9 \\
\hline Ireland & 38856.9 & 5.1 & 42.2 & 46.7 \\
\hline Israel & 25392.0 & 4.6 & 51.9 & 44.6 \\
\hline Japan & 34268.4 & 4.9 & 48.6 & 49.9 \\
\hline Korea, Republic of & 24360.7 & 5.3 & 44.5 & 43.2 \\
\hline Latvia & 14473.3 & 5.4 & 41.1 & 44.6 \\
\hline Netherlands & 40905.3 & 4.8 & 53.9 & 49.6 \\
\hline New Zealand & 28641.5 & 5.0 & 48.5 & 50.1 \\
\hline Norway & 54183.7 & 5.4 & 47.6 & 46.9 \\
\hline Poland & 14782.2 & 5.2 & 48.2 & 48.1 \\
\hline Portugal & 21051.6 & 4.4 & 40.2 & 49.3 \\
\hline Slovenia & 25510.6 & 5.4 & 46.9 & 46.6 \\
\hline Spain & 29632.6 & 4.6 & 48.5 & 47.2 \\
\hline Sweden & 37506.3 & 5.3 & 46.7 & 48.1 \\
\hline Switzerland & 39951.3 & 5.4 & 42.5 & 50.5 \\
\hline USA & 44663.5 & 5.3 & 46.6 & 47.1 \\
\hline
\end{tabular}


Editor

Dr. Romana Careja

\section{Editorial Board}

Professor Dr. Hans-Jürgen Andreß

Professor Dr. Detlef Fetchenhauer

Professor Dr. Axel Franzen

Professor Dr. Martina Fuchs

Professor Dr. Clemens Fuest

Professor Dr. Karsten Hank

Professor Dr. Marita Jacobs

Professor Dr. Wolfgang Jagodzinski

Professor Dr. André Kaiser

Professor Dr. Heiner Meulemann,

Professor Dr. Sigrid Quack

Professor Dr. Ingo Rohlfing

Professor Dr. Frank Schultz-Nieswandt

Professor Dr. Friedrich Schmid

Professor Dr. Elmar Schlüter

Professor Dr. Christine Trampusch

Professor Dr. Michael Wagner
The GK SOCLIFE working paper series are published by the Research Training Group SOCLIFE, an interdisciplinary research training group, which is at the crossroads between social and economic sciences, statistics and law. The Research Training Group SOCLIFE develops under the aegis of the Faculty of Economic and Social Sciences of the University of Cologne. The working papers are meant to share work in progress before formal publication. The aim of the series is to promote conceptual, methodological and substantial discussion between the members of SOCLIFE and the larger scholar community.

Submissions. Papers are invited from all the members of Research Training Group SOCLIFE, and also from other interested scholars. All papers are subject to review by one member of the Editorial Board. Papers can be submitted either in English or in German. Authors interested in including their work in the GK SOCLIFE series may send their papers to soclife-workingpaperseries@wiso.uni-koeln.de.

Access. The working papers series can be accessed at http://www.soclife.unikoeln.de/index.php?id=11863. Comments on the papers should be sent directly to the authors.

All rights reserved.

http://www.soclife.uni-koeln.de/index.php?id=11863 